Article

\title{
Spatiotemporal Variation of Urban Heat Islands for Implementing Nature-Based Solutions: A Case Study of Kurunegala, Sri Lanka
}

\author{
Manjula Ranagalage ${ }^{1,2, *}$, Sujith S. Ratnayake ${ }^{3,4}$, DMSLB Dissanayake ${ }^{1}{ }^{(}$, Lalit Kumar $^{4}(\mathbb{D}$, \\ Hasula Wickremasinghe ${ }^{3}$, Jagathdeva Vidanagama ${ }^{5}$, Hanna Cho ${ }^{6}$, Susantha Udagedara ${ }^{7}$ (D), \\ Keshav Kumar Jha ${ }^{8}$, Matamyo Simwanda ${ }^{9}$ (D), Darius Phiri ${ }^{9}\left(\mathbb{D}\right.$, ENC Perera $^{10}$ and \\ Priyantha Muthunayake ${ }^{11}$ \\ 1 Department of Environmental Management, Faculty of Social Sciences and Humanities, \\ Rajarata University of Sri Lanka, Mihintale 50300, Sri Lanka; dissanayakedmslb@ssh.rjt.ac.lk \\ 2 Faculty of Life and Environmental Sciences, University of Tsukuba, 1-1-1, Tennodai, Tsukuba, \\ Ibaraki 305-8572, Japan \\ 3 Climate Change Secretariat, Ministry of Environment and Wildlife Resources, Battaramulla 10120, Sri Lanka; \\ rratnaya@une.edu.au (S.S.R.); hasulaw@yahoo.com (H.W.) \\ 4 Ecosystem Management Division, School of Environmental and Rural Science, University of New England, \\ Armidale, NSW 2350, Australia; lkumar@une.edu.au \\ 5 Department of Zoology and Environment Sciences, Faculty of Science, University of Colombo, \\ Colombo 10120, Sri Lanka; jagathdevav@zoology.cmb.ac.lk \\ 6 Korea Environment Institute, 5F, Bldg B, 232, Gareum-ro, Sejong 30121, Korea; hncho@kei.re.kr \\ 7 Blue Resources Trust, 86, Barnce Place, Colombo 00700, Sri Lanka; susantha@blueresources.org \\ 8 ICLEI-Local Governments for Sustainability, South Asia, vC-3, Lower Ground Floor, Green Park Extension, \\ New Delhi 110016, India; keshav.jha@iclei.org \\ 9 Department of Plant and Environmental Sciences, School of Natural Resources, Copperbelt University, \\ P.O. Box 21692, Kitwe 10101, Zambia; matamyo.simwanda@cbu.ac.zm (M.S.); \\ dariusphiri@rocketmail.com (D.P.) \\ 10 Department of Regional Science and Planning, SANASA Campus, Kegalle 71000, Sri Lanka; \\ chinssu@gmail.com \\ 11 Municipal Council, Kurunegala 60000, Sri Lanka; mohmck0@gmail.com \\ * Correspondence: manjularanagalage@ssh.rjt.ac.lk
}

Received: 28 May 2020; Accepted: 14 July 2020; Published: 21 July 2020

check for updates

\begin{abstract}
Changes in the urban landscape resulting from rapid urbanisation and climate change have the potential to increase land surface temperature (LST) and the incidence of the urban heat island (UHI). An increase in urban heat directly affects urban livelihoods and systems. This study investigated the spatiotemporal variation of the UHI in the Kurunegala urban area (KUA) of North-Western Province, Sri Lanka. The KUA is one of the most intensively developing economic and administrative capitals in Sri Lanka with an urban system that is facing climate vulnerabilities and challenges of extreme heat conditions. We examined the UHI formation for the period 1996-2019 and its impact on the urban-systems by exploring nature-based solutions (NBS). This study used annual median temperatures based on Landsat data from 1996 to 2019 using the Google Earth Engine (GEE). Various geospatial approaches, including spectral index-based land use/cover mapping (1996, 2009 and 2019), urban-rural gradient zones, UHI profile, statistics and grid-based analysis, were used to analyse the data. The results revealed that the mean LST increased by $5.5^{\circ} \mathrm{C}$ between 1996 and 2019 mainly associated with the expansion pattern of impervious surfaces. The mean LST had a positive correlation with impervious surfaces and a negative correlation with the green spaces in all the three time-points. Impacts due to climate change, including positive temperature and negative rainfall anomalies, contributed to the increase in LST. The study recommends interactively applying NBS to addressing the UHI impacts with effective mitigation and adaptation measures for urban sustainability.
\end{abstract}


Keywords: LST; UHI; impervious surface; green surface; climate change; NBS; Kurunegala; Sri Lanka

\section{Introduction}

Sri Lanka has shown stable economic growth over the last few decades, which has led to the country being categorized as an upper-middle-income country in 2018 [1]. From 1960 to 2018, the otal population of Sri Lanka increased by 11.8 million (119.5\%) [2], while the urban population also increased by 2.4 million (146.8\%) [3]. Additionally, Sri Lanka has experienced rapid economic growth after 30 years of civil war that ended in 2009, with a 5.6\% economic development between 2010 and 2018 [4]. As the centre of the South Asian region, Sri Lanka is considered as a central node in the proposed "21st Century Maritime Silk Road" [5]. The central location of the country is directly impacted by rapid mega-development projects such as megacity expansion, airports, harbours, urban beautification and highways, especially during the last ten years [6]. The last decade has seen most of the expressways construction and development projects such as Southern, Outer Circular, Colombo-Katunayake and Andarawewa-Hambantota that were implemented to enhance the economic development of the country $[7,8]$. This rapid development of the transportation systems resulted in increasing urbanisation, which has a direct impact on the urban population of up to 4.0 million (18\% of the total population). However, the negative impacts associated with urbanisation have increased during the past few decades [9].

Urbanisation provides socio-economic development; however, this development has negative impacts on natural environments [10]. The rapid increase of the urban population, increased use of grey infrastructure, high energy usage, conversion of agricultural land to industrial sites together with high environmental pollution levels have directly affected the urban ecosystem health and human wellbeing in Sri Lanka [11]. During the past few decades, most of the green areas and wetlands in urban and peri-urban areas in Sri Lanka have been converted to impervious surfaces (IS) [12]. These rapid conversions have resulted in several negative impacts, such as air pollution [13], decreasing green surface (GS) [9], declining agricultural lands [14,15], increasing vector-borne diseases [16], water pollution [17], declining wetlands [18] and increasing Urban Heat Island (UHI) [19].

The UHI is a phenomenon that refers to the aspect that urban areas are warmer compared to rural surroundings [20]. In other words, a UHI refers to an urban region that is altogether hotter than its surrounding rural regions due to human activities. The daytime and night-time surface temperature differences between developed and rural areas have been reported to range from $10{ }^{\circ} \mathrm{C}$ to $15{ }^{\circ} \mathrm{C}$ and $5{ }^{\circ} \mathrm{C}$ to $10{ }^{\circ} \mathrm{C}$, respectively [20]. The UHI exists regardless of city size, although, its magnitude varies depending on the size of the city [20]. There are several negative impacts associated with $\mathrm{UHI}$ in urban areas. These include energy balance changes [21], heat-related human illness and discomfort [20], increasing air pollutants [20], impaired water quality [20] and increased mortality among older people [22]. In addition, the increase of the ambient temperature due to the UHI has a direct impact on increasing the Green House Gas (GHG) emissions associated with energy use in the buildings [23-25]. As a result of these effects, UHI has now become an urgent research topic [26].

The UHI can be calculated based on air temperature and land surface temperature (LST) [20]. However, conducting UHI studies by using air temperature is challenging, especially in developing countries where meteorological stations and ground-based data are lacking or sparse [20]. Thus, UHI studies based on land surface temperature (LST) derived from remote sensing (RS) data have become common among researchers due to its spatial extent and temporal availability [27]. The rapid development of RS data and geospatial analysis has significantly enhanced UHI studies during the past three decades $[28,29]$. Past studies have mainly used the relationship between mean LST and two primary land use/cover (LULC) types (i.e., impervious surfaces (IS) and green spaces (GS)) to understand the UHI effect in several cities such as mountainous cities [9,30], coastal cities [26,31] and inland cities [31-33]. There are several approaches for the extraction of land use/land cover (LULC) 
information such as pixel- and object-based [34,35] and spectral index-based methods. Among these methods, the spectral index-based method has been proven to be the most effective $[26,31,36,37]$ especially in recent UHI studies [19,31,32].

On the other hand, to have a comprehensive understanding of the UHI distribution various approaches have been used. For example, to understand the temperature difference between the urban and rural zones, the urban-rural gradient analysis has been employed by several studies [30,31,38]. However, due to the inability to capture the directional deviation of the UHI through gradient analysis, other researchers employ the multitemporal and multidirectional UHI profile analysis over the orthogonal and diagonal directions of their respective cities $[30,32]$. Other previous studies have, additionally, employed the grid-based method to understand the relationship between LST and the fraction of IS and GS in their cities $[26,39,40]$.

The UHI is considered as one of the byproducts of rapid urbanisation, and many mitigation methods have been studied and proposed by previous researchers. Some of the mitigation methods that have been proposed include (i) increasing vegetation cover; (ii) creating green roofs; (iii) use of cool roofs; (iv) use of cool pavements; and (v) smart growth by protecting the natural environment in urban areas [20,41-43]. Among these mitigation measures proposed, green infrastructure can be easily implemented in urban areas [44]. Green cover reduces air temperature [45] and decreases the surface temperature in urban areas [46]. Thus, natural ecosystems can be used to provide benefits to the urban climate and environments by increasing street trees, green walls and green roofs [44]. Nature-based solutions (NBS) have been identified as a key possible solution to mitigate the UHI in developing counties, more especially in small cities. NBS can be implemented in small cities, compared to highly developed saturated cities. The scientific literature provides different interpretations of the NBS at different levels $[47,48]$. However, the most prominent is by the European Commission, defining NBS as "actions which are inspired by, supported by or copied from nature" with "the aim to help societies address a variety of environmental, social and economic challenges in sustainable ways" [49]. The IUCN (Cohen-Shacham et al., 2016) [50] definition also shares similar ideas-providing co-benefits for human well-being and societal challenges while building climate resilience [50]. Thus, studying the spatiotemporal patterns of the UHI in specific cities in important to come up with the appropriate NBS mitigation measures [51].

In Sri Lanka, most of the past UHI studies focused on the cities which are located in diverse geographical zones including coastal cities (e.g., Colombo [12,19,52] and Galle [53]) and mountain cities (e.g., Kandy, and Nuwara Eliya $[9,15,54,55]$ ). The findings of these previous studies provide sufficient information to understand the UHI pattern and to enhance remedial measures to control the negative impacts associated with UHI. However, research on small, rapidly developing cities in Sri Lanka is still lacking. Thus, understanding the spatiotemporal pattern of the UHI in small cities is required for coming up with proper NBS that can control the UHI effect. In recent past decades, Kurunegala Urban Area (KUA), has been identified as a developing centre and future hotspot [56]. Therefore, in this study, we hereinto hypothesize that rapid development has significantly influenced the occurrence of UHI in the KUA. The aim of the study is to examine the spatiotemporal variation of the UHI formation for the period 1996-2019 and its impact on the urban-systems as well as exploring NBS towards the urban sustainability of the KUA. The study used annual median temperatures based on Landsat data (1996 to 2019) using the Google Earth Engine (GEE). Various geospatial approaches, including spectral index-based land use/cover mapping (1996, 2009 and 2019), urban-rural gradient zones, UHI profile, statistics and grid-based analysis, were used to future comprehend the UHI in the KUA. The study finally ends with a discussion on the application of NBS to addressing the UHI impacts with effective mitigation and adaptation measures for urban sustainability. 


\section{Materials and Methods}

\subsection{Study Area: KUA, Sri Lanka}

Kurunegala is the largest city in the North-Western Province of Sri Lanka. According to the 2012 statistical information from the Sri Lankan Department of Census and Statistics, the total population of Kurunegala District was more than 1.6 million representing approximately $7.9 \%$ of the total population of Sri Lanka [57]. The geographical location of the KUA extends from latitude $7^{\circ} 22^{\prime} 2.81^{\prime \prime} \mathrm{N}$ to $7^{\circ} 41^{\prime} 16.74^{\prime \prime} \mathrm{N}$ and from longitude $80^{\circ} 16^{\prime} 14.51^{\prime \prime} \mathrm{E}$ to $80^{\circ} 26^{\prime} 46.89^{\prime \prime} \mathrm{E}$ (Figure 1 ). The KUA consists of the city centre (Kurunegala Municipal Council) and the surrounding peri-urban areas (Divisional Secretariats Division). KUA is located in an intermediate climate zone in the lowland country region with a tropical hot, humid climate. The area experiences heavy rain from May to August and from October to January every year. The average annual precipitation is about $2000 \mathrm{~mm}$. The annual mean, maximum and minimum temperatures are $27.7^{\circ} \mathrm{C}, 32.1^{\circ} \mathrm{C}$ and $23.2^{\circ} \mathrm{C}$, respectively. January is the hottest and driest month of the year.


Figure 1. The study area in Sri Lanka: (a) map from part of South Asia; (b) location of the Kurunegala Urban Area (KUA) in Sri Lanka; and (c) Landsat-8 false-colour composite image (bands 5, 4 and 3) of 2019 showing the study area. 


\subsection{Overall Workflow}

Figure 2 shows the overall workflow of the study to achieve the objective mention above.

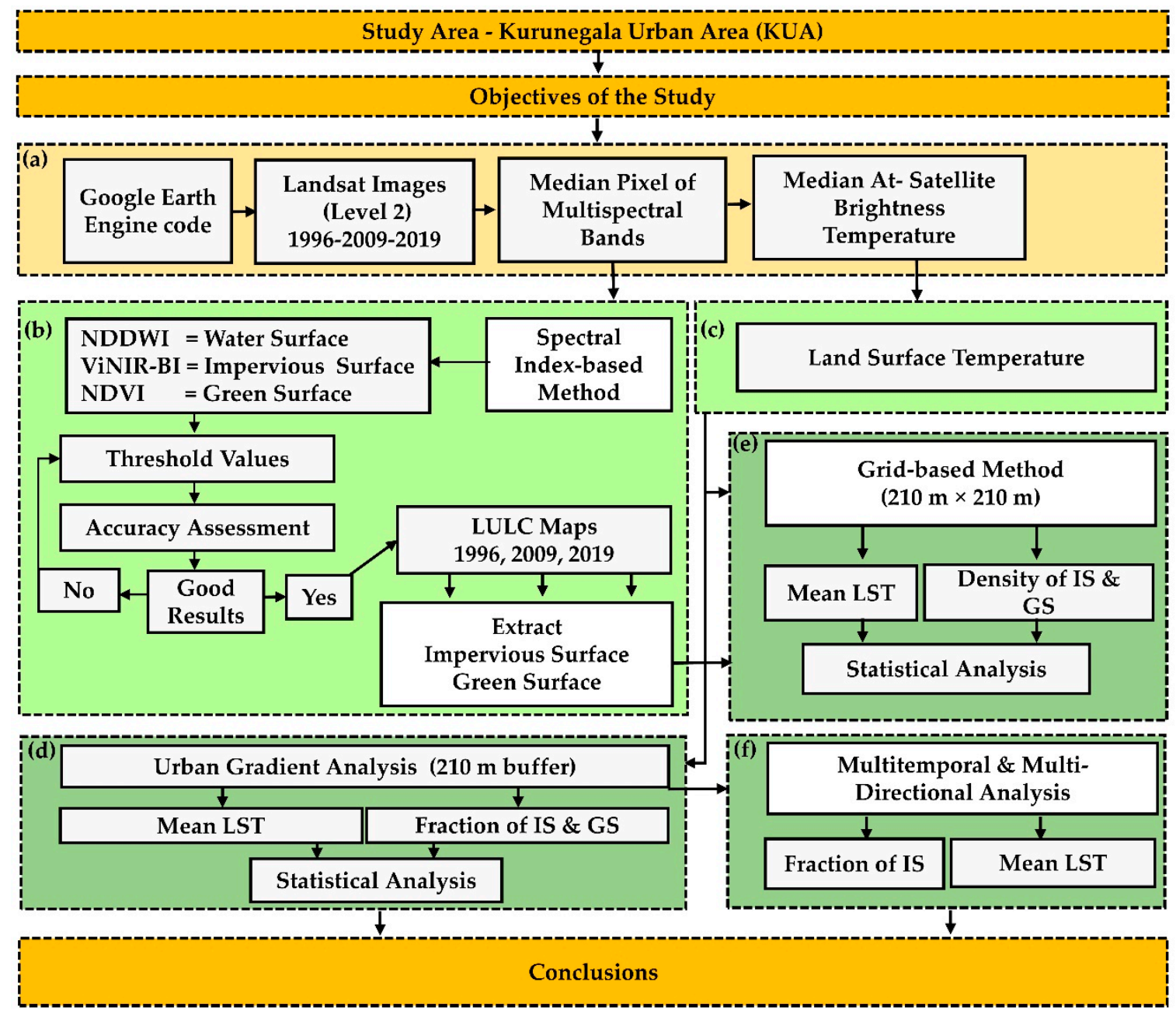

Figure 2. The workflow of the study: (a) use of Google Earth Engine (GEE) to extract bands of Landsat images; (b) land cover extraction; (c) Land Surface Temperature (LST) retrieval; (d) use of urban gradient analysis; (e) use of the grid-based method; and (f) use of multitemporal and multi-directional analysis.

\subsection{Data}

The Google Earth Engine (GEE) was used to extract the annual median pixel for the time point (1996, 2009 and 2019) in this study. GEE used pre-processed atmospherically corrected Landsat (Level 2) images to provide an annual median pixel for each band at a particular time point. Image collection in GEE used 16 images for 1996 (Landsat 5), 18 images for 2009 (Landsat 5) and 18 images for 2019 (Landsat 8) (Table A1). The process used in this study was as follows:

I. The Surface Reflectance (annual median pixel) of the multispectral bands (Blue, Green, Red, near-infrared (NIR), Short-wave infrared (SWIR) 1 and Short-wave infrared (SWIR) 2), was extracted based on the GEE algorithms. Our assumption here was that the annual median pixel provides precise information regarding the land cover in the study area [58]. In this section, we used less than $10 \%$ cloud cover images. We then extracted the multispectral bands used to detect land cover changes based on the spectral index-based method described in Section 2.4.

II. KUA is in the intermediate zone of Sri Lanka, and it does not have a seasonal variation in temperature. Thus, we used annual median temperatures based on the upper-atmosphere 
brightness temperature using thermal bands (band 6 and 10 for Landsat 5 and 8, respectively) based on the GEE. Several past studies have used annual median temperature and achieved accurate results $[15,59,60]$ Extracted median temperatures of the thermal bands were used to derive the LSTs, as described in Section 2.5.

\subsection{Land Cover Extraction and Accuracy Assessment}

The land cover for the study area was extracted based on the spectral index-based method by classifying the images into four classes: impervious surface (IS), green space (GS), water and other surfaces comprising all other areas excluding IS, GS and water. This method has been used by previous researchers $[26,31,36]$. The details of the land cover extraction are as follows:

I. The water class was extracted using the modified normalized difference water index (MNDWI) (Equation (1)) [26,31]. We then used the Otsu's optimal binary thresholding technique to exclude the water class from the other classes $[61,62]$.

$$
\text { MNDWI }=\frac{(\text { Green }- \text { SWIR1 })}{(\text { Green }+ \text { SWIR1 })}
$$

where Green is band 2 for Landsat- 5 TM and band 3 for Landsat- 8 , while SWIR1 is band 5 for Landsat-5 TM and band 6 for Landsat-8.

II. The IS class was extracted using the visible Red and NIR based built-up index (VrNIR-BI) using Equation (2). The VrNIR-BI has been used in previous studies and proven to produce higher accuracies compared to other built-up indices [36]. The water class was masked off before the extraction of the IS in each year. Manual thresholding was applied to extract VrNIR-BI after several threshold values were tested by examining Google Earth images and colour composite (true and false) Landsat images of the study area. Finally, $-0.478,-0.478$ and -0.577 thresholds values were used for 1996, 2009 and 2019, respectively.

$$
\operatorname{VrNIR}-\mathrm{BI}=\frac{(\mathrm{RED}-\mathrm{NIR})}{(\mathrm{RED}+\mathrm{NIR})}
$$

where RED is band 3 for Landsat- 5 TM and band 4 for Landsat 8 , while NIR is band 4 for Landsat- 5 TM and band 4 for Landsat-8 [36].

III. The GS class was extracted by using the normalized difference vegetation index (NDVI) using Equation (3). Before the extraction of the GS, the IS and water classes were masked from the NDVI maps. Then, limit values were physically calibrated utilizing Google Earth and colour composite (true and false) images for the study area. Finally, the NDVI values of 0.625 for 1996, 0.625 for 2009 and 0.737 for 2019 were used as threshold values for GS extraction. Other areas less than 0.625 for 1996, 0.625 for 2009 and 0.737 for 2019 were used to classify the "Other" class of the study area.

$$
\mathrm{NDVI}=\frac{(\mathrm{NIR}-\mathrm{RED})}{(\mathrm{NIR}+\mathrm{RED})}
$$

where NIR is band 4 for Landsat 5 TM and band 5 for Landsat-8, while RED is band 3 for Landsat- 5 TM and band 4 for Landsat-8 [63,64].

After extraction of all the land cover classes, the accuracy of the classified land cover maps was investigated by using 300 random points. A topographic map of the KUA was used to assess the accuracy of the 1996 land cover map due to the unavailability of Google Earth imagery at that time. The accuracies of the 2009 and 2019 land cover maps were assessed using Google Earth imagery with capture dates close to or at the same time as the land cover maps. The ground truth data from the topographic map (1996) and Google Earth imagery (2009 and 2019) obtained for the reference points 
were then compared to the actual points from the classified land cover maps and used to calculate the accuracy [65].

\subsection{LST Retrieval}

The at-satellite brightness temperatures (annual median), which were extracted in Section 2.2, were used to calculate the LST. Before calculating LST, at-satellite brightness temperatures $\left(T_{B}\right)$ were scaled using land surface emissivity values [63]. The land surface emissivity was derived using the NDVI method [63]. After calculating emissivity, the calculated values were used to derive the LST values by using Equation (4).

$$
\mathrm{LST}=\mathrm{T}_{\mathrm{B}} / 1+\left(\lambda \times \mathrm{T}_{\mathrm{B}} / \varrho\right) \ln \varepsilon
$$

where $T_{B}$ is the Landsat TM Band 6 at-satellite brightness temperature in Kelvin; $\lambda$ is the wavelength of the emitted radiance $(\lambda=11.5 \mu \mathrm{M}$ for Landsat- 5 TM band 6 [66], $\lambda=10.8 \mu \mathrm{M}$ for Landsat- 8 thermal infrared sensor (TIRS ) band 10 [30]); $\varrho=\mathrm{h} \times \mathrm{c} / \sigma\left(1.438 \times 10^{-2} \mathrm{~m} \mathrm{~K}\right) ; \sigma=$ the Boltzmann constant $\left(1.38 \times 10^{-23} \mathrm{~J} / \mathrm{K}\right) ; \mathrm{h}=$ Planck's constant $\left(6.626 \times 10^{-34} \mathrm{~J} \mathrm{~s}\right) ; \mathrm{c}=$ the velocity of light $\left(2.998 \times 10^{8} \mathrm{~m} / \mathrm{s}\right) ;$ and $\varepsilon$ is the land surface emissivity valued by the NDVI method [63]. Last, LST values converted from Kelvin to degrees Celsius $\left({ }^{\circ} \mathrm{C}\right)[67,68]$.

\subsection{Urban-Rural Gradient Zone (URGZ) and UHI Profile Analysis}

The UHI distribution, the faction of IS (FIS) and the fraction of GS (FGS) were examined using the urban-rural gradient analysis method. The urban-rural gradient analysis method has been used widely, especially in single-core cities, to find the spatial variation of LST, FIS and FGS [26,30]. In this study, we used several steps to formulate the URGZs. First, $210 \mathrm{~m} \times 210 \mathrm{~m}$ fishnets were created by snapping the Landsat images. Second, twenty-three URGZs were created by assigning the city centre grid as 0 grid. Then, the mean LST, FIS and FGS were calculated in each URGZ using zonal statistics. Finally, we used linear regression analysis and scatter plots to analyse the relationship between the mean LST and the FIS, and FGS.

In order to create multitemporal and multi-directional UHI profiles, the mean LST, FIS and FGS were extracted by following the orthogonal and diagonal directions of the study area, such as northwest-southeast, northeast-southwest, east-west and north-south [30,32].

\subsection{Grid-Based Analysis}

The grid-based method was used to identify the spatial patterns and of the mean LST with FIS, and FGS as well as their respective statistical relationships. In this analysis, a $210 \mathrm{~m} \times 210 \mathrm{~m}$ $(7 \times 7$ pixels $)$ grid size was used. Previous studies have shown that the $210 \mathrm{~m} \times 210 \mathrm{~m}$ grid produces better correlation results than other grid sizes [15,26,40]. The "Fishnet tool" available in ArcGIS 10.6 (ESRI, United States) using the same snapping of the Landsat images were used to create the sets of grids. Then, the mean LST, FIS and FGS of each grid were extracted. Finally, linear regression analysis and scatter plots were used to examine the relationship of mean LST with the FIS and FGS.

\section{Results}

\subsection{Accuracy Assessment and Landscape Changes}

The accuracy assessment of the classified land cover maps recorded overall accuracies of $83 \%$, $83 \%$ and $88 \%$ for the years 1996, 2009 and 2019, respectively. The accuracies recorded exceed the recommended minimum standard (80\%) [69] and were considered satisfactory for monitoring the landscape changes and LST in the study area.

Table 1 shows the land cover changes in the KUA during the study temporal extent. The results reveal that KUA has been experiencing rapid urban expansion during the past 23 years (Figure 3). The IS areas increased from 158.9 ha (1.6\%) in 1996 to 463.8 ha (4.6\%) in 2009. By 2019, the IS areas increased 
to 1089.3 ha (10.8\%). The fast growth of the IS areas occurred at the expense of GSs; GSs reduced from 6713.6 ha in 1996 to 5436.5 ha by 2019 (Table 1).

Table 1. Land cover changes in the Kurunegala urban area (KUA) area.

\begin{tabular}{|c|c|c|c|c|c|c|c|c|c|c|c|c|}
\hline \multirow{3}{*}{$\begin{array}{c}\text { Land Cover } \\
\text { Class }\end{array}$} & \multicolumn{6}{|c|}{ Land Cover } & \multicolumn{6}{|c|}{ Land Cover Changes } \\
\hline & \multicolumn{2}{|c|}{1996} & \multicolumn{2}{|c|}{2009} & \multicolumn{2}{|c|}{2019} & \multicolumn{2}{|c|}{ 1996-2009 } & \multicolumn{2}{|c|}{ 2009-2019 } & \multicolumn{2}{|c|}{ 1996-2019 } \\
\hline & ha & $\%$ & ha & $\%$ & ha & $\%$ & ha & $\mathrm{AGR}^{1}$ & ha & AGR & ha & AGR \\
\hline IS & 158.9 & 1.6 & 463.8 & 4.6 & 1089.3 & 10.8 & 304.9 & 23.5 & 625.5 & 62.6 & 930.4 & 40.5 \\
\hline GS & 6713.6 & 66.9 & 5883.9 & 58.6 & 5436.5 & 54.1 & -829.6 & -63.8 & -447.4 & -44.7 & -1277.0 & -55.5 \\
\hline Other & 3108.3 & 31.0 & 3626.9 & 36.1 & 3439.7 & 34.3 & 518.6 & 39.9 & -187.2 & -18.7 & 331.4 & 14.4 \\
\hline Water & 59.3 & 0.6 & 65.4 & 0.7 & 74.5 & 0.7 & 6.1 & 0.5 & 9.1 & 0.9 & 15.2 & 0.7 \\
\hline
\end{tabular}

Note: $\mathrm{AGR}^{1}$ is the annual growth rate measured in ha per year.
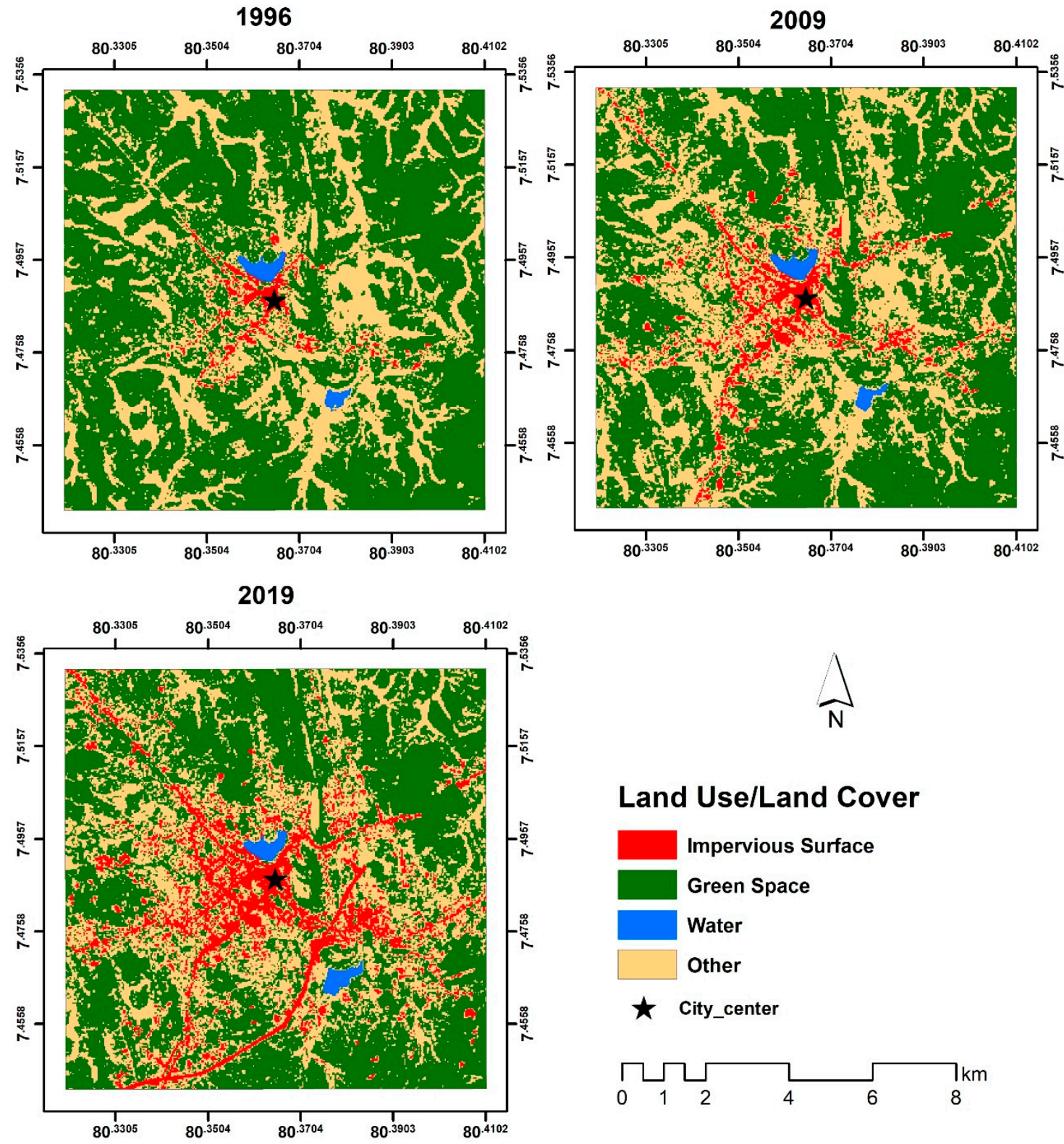

\section{Land Use/Land Cover}
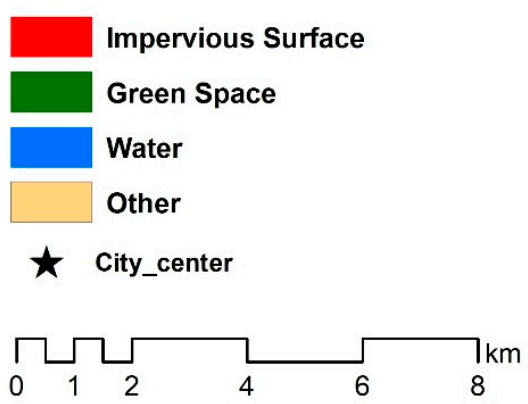

Figure 3. Land use land cover maps of the KUA for 1996, 2009 and 2019. 


\subsection{LST Distribution}

Figure 4 shows the LST distribution of the KUA in 1996, 2009 and 2019. In 1996, LST ranged from $17.7^{\circ} \mathrm{C}$ to $26.5^{\circ} \mathrm{C}$ with a mean of $21.6^{\circ} \mathrm{C}$; in 2009 , LST ranged from $19.5^{\circ} \mathrm{C}$ to $28.4^{\circ} \mathrm{C}$ with a mean of $23.5^{\circ} \mathrm{C}$; and in 2019 , LST ranged from $23.0^{\circ} \mathrm{C}$ to $32.1{ }^{\circ} \mathrm{C}$ with a mean of $26.5^{\circ} \mathrm{C}$.

In 1996, the distribution of high LST values was concentrated around the city centre. Areas with the lowest LST values were located mainly in the north and south areas of the city. In 2009, the spatial pattern of LST started expanding around the city core area as more areas recorded higher LST. In 2019, the city core and its surrounding areas recorded higher LST values distributed mainly towards the western and eastern parts of the city (Figure 4). High LST was observed to be mostly associated with the distribution of IS in all the three-time points.

Table 2a shows the mean LST and its changes within the IS and the GS areas from 1996 to 2019. The results show that the mean LST of the IS areas increased by $5.5^{\circ} \mathrm{C}$ between 1996 and 2019. The results further revealed that the degree of the mean LST between the IS and GS increased by an average value of $1.0^{\circ} \mathrm{C}$.
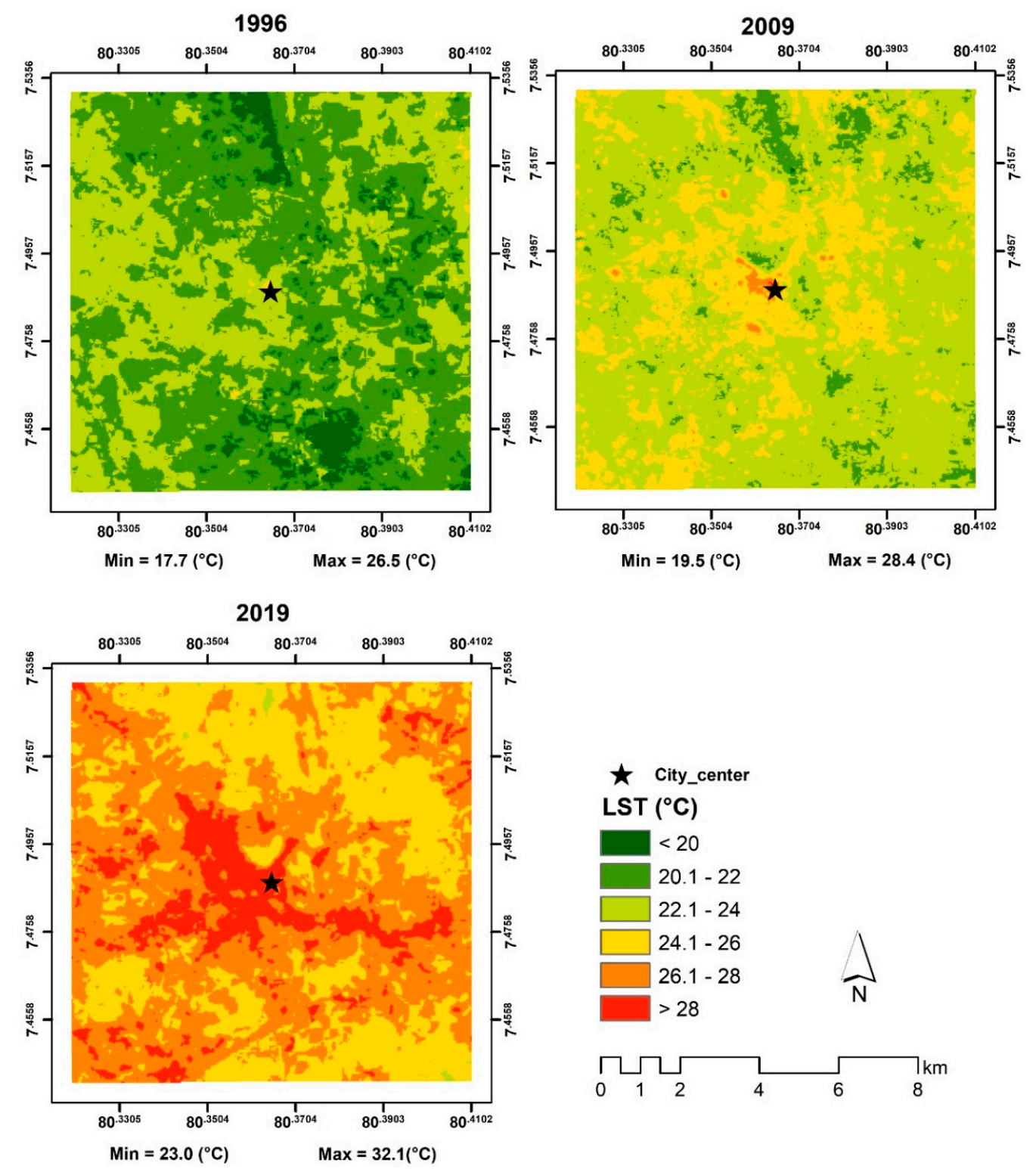

Figure 4. LST map of the KUA for 1996, 2009 and 2019. 
Table 2. Mean LST for the impervious surfaces (IS) and the green surface (GS), and the magnitude of urban heat island (UHI) in ${ }^{\circ} \mathrm{C}$.

\begin{tabular}{|c|c|c|c|c|}
\hline \multicolumn{5}{|c|}{ (a) Mean LST of IS and GS $\left({ }^{\circ} \mathrm{C}\right)$} \\
\hline Land cover Class & 1996 & 2009 & 2019 & Change (1996-2019) \\
\hline IS & 22.7 & 24.8 & 28.2 & 5.5 \\
\hline GS & 21.5 & 23.2 & 26.0 & 4.6 \\
\hline \multicolumn{5}{|c|}{ (b) The Magnitude of LST $\left({ }^{\circ} \mathrm{C}\right)$} \\
\hline \multirow{2}{*}{ Cross-cover comparison } & \multicolumn{3}{|c|}{$\Delta$ Mean-LST } & \multirow{2}{*}{ Change (1996-2019) } \\
\hline & 1996 & 2009 & 2019 & \\
\hline IS-GS & 1.2 & 1.7 & 2.2 & 1.0 \\
\hline
\end{tabular}

\subsection{LST Distribution Pattern along the URGZ}

Figure 5 shows the spatial distribution of mean LST and the FIS and FGS along the URGZs from 1996 to 2019. The maximum mean LST was recorded in the city centre zone (URGZ 1 ) with values of $23.2^{\circ} \mathrm{C}, 25.8^{\circ} \mathrm{C}$ and $29.4{ }^{\circ} \mathrm{C}$ for 1996,2009 and 2019, respectively. According to Figure 5, the mean LST of each URGZ increased between 1996 and 2019. However, most of the increase in mean LST was observed during the 2009 to 2019 period.

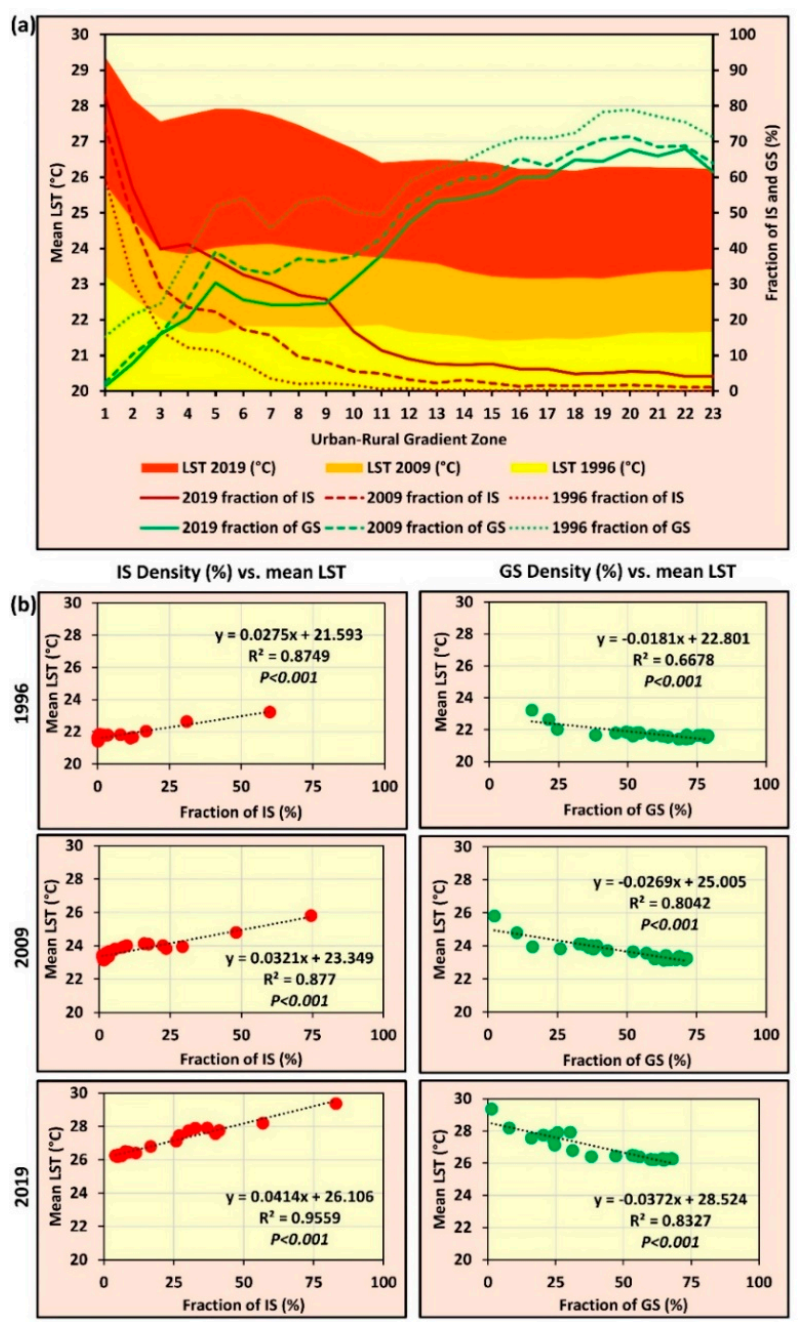

Figure 5. (a) The spatial pattern of mean LST, and the faction of IS (FIS) and the fraction of GS (FGS); (b) results of linear regression analysis along URGZ, 1996, 2009 and 2019. 
The average FIS was observed to increase while the FGS decreased within the city centre zone (URGZ ${ }_{1}$ ) (Figure $5 \mathrm{a}$ ). The FIS increased by $59.9 \%, 74.5 \%$ and $82.9 \%$, and the FGS decreased by $15.3 \%$, $2.3 \%$ and $1.3 \%$ in 1996, 2009 and 2019, respectively. The statistical analysis showed a strong positive correlation $(p<0.001)$ between the FIS and the mean LST. Conversely, the mean LST showed a strong negative relationship $(p<0.001)$ with the FGS for all the three-time steps (i.e., 1996, 2009 and 2019) (Figure 5b).

\subsection{UHI Profiles}

Multi-directional and multi-temporal profiles of the mean LST and the FIS are shown in Figure 6. The mean LST for each direction showed an increasing pattern. This association between the FIS and the mean LST is notable in Figure 6. Generally, the mean LST increasing pattern was closely associated with the spatial distribution of the FIS. Accordingly, high LST values and high FIS were located around the city centre.
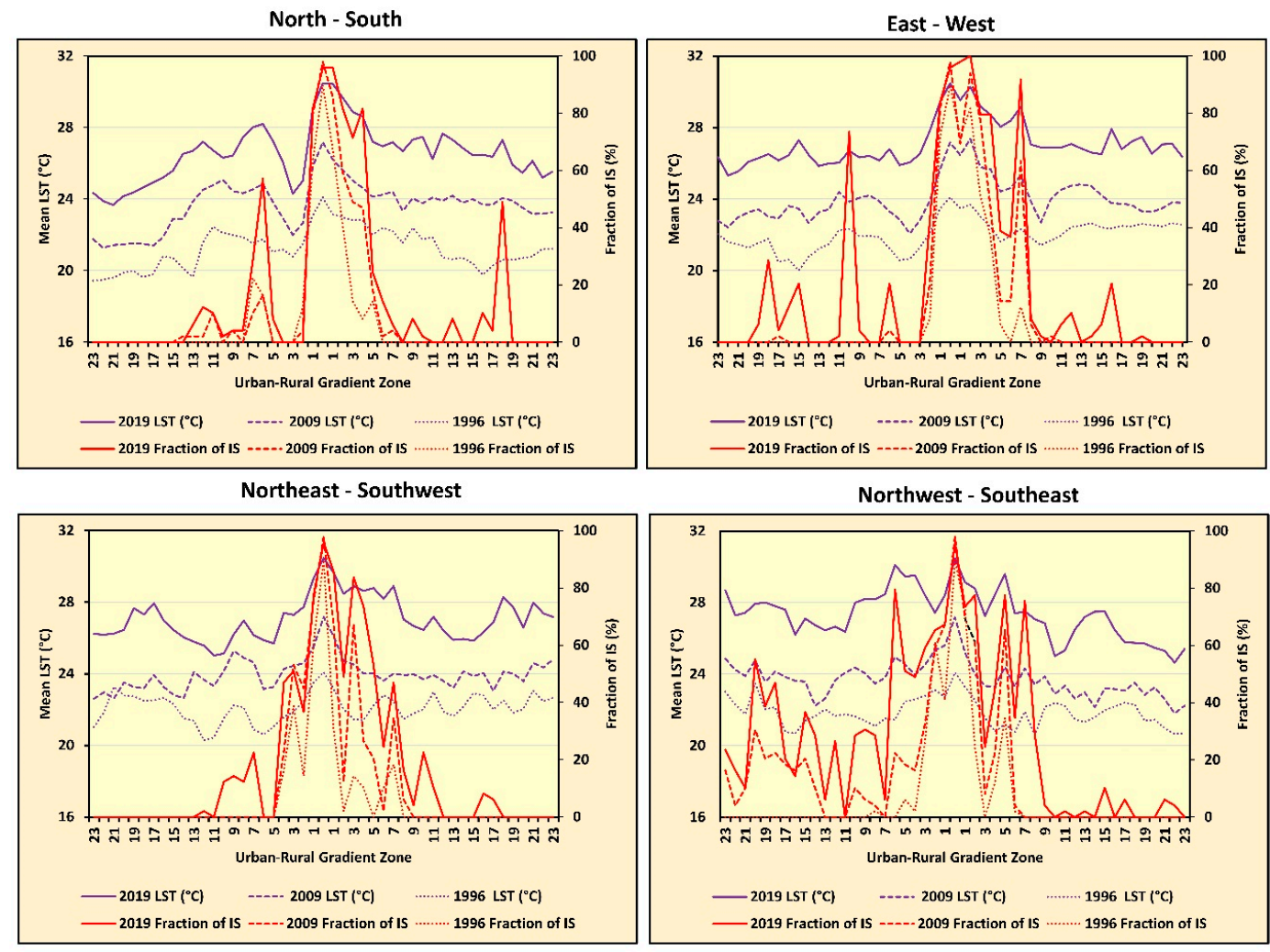

Figure 6. Multi-directional UHI profiles of KUA based on the mean LST and the FIS in 1996, 2009 and 2019.

\subsection{FIS and FGS Associated with Mean LST Based on the Grid-Based Method}

The spatial patterns of the mean LST, FIS and FGS are shown in Figure 7a. Areas with high accumulated LST values were observed around the city centre at all the three-time points (1996, 2009 and 2019). By 2019, high LST values were mainly distributed towards the west, east and the north-eastern directions of the study area. The FIS was mainly observed near the city centre in 1996 and was later distributed towards the south, east and west side of the study area by 2009. However, a considerable difference was observed in 2019 with high mean LST values spreading in all the seven directions. The FGS declined substantially between 1996 and 2019. In 1996, the GS areas can be seen throughout the KUA but then noticeably disappeared by 2019, especially around the city centre area. In 2019, the low FGS can only be seen in the north, north-eastern and the south-eastern direction of the study area. The statistical analysis revealed a strong positive relationship $(p<0.001)$ between the 
mean LST and the FIS. The statistical relationship between mean LST and the FGS had a significantly negative $(p<0.001)$ throughout the 1996 to 2019 period (Figure $7 \mathrm{~b}$ ).
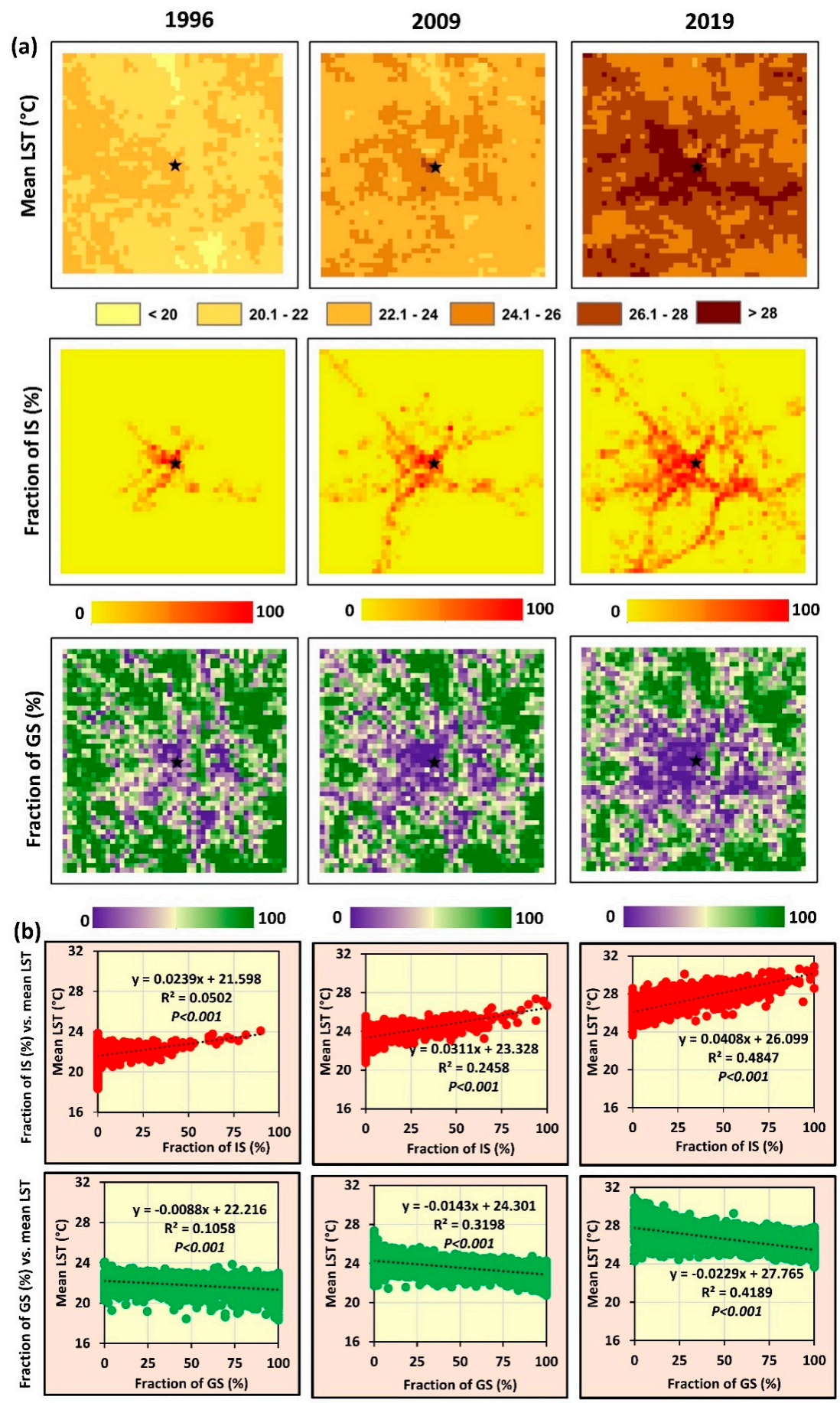

Figure 7. (a) Graphical view of the $210 \times 210 \mathrm{~m}$ polygon grid showing maps of the Mean Land Surface Temperature (MLST), the fraction of IS (\%) and the GS (\%), (b) Scatterplots showing the relationship between the fraction of IS (\%), GS (\%) and mean LST in 1996, 2009 and 2019.

\section{Discussion}

\subsection{Urbanisation in the KUA}

The results show that the KUA experienced rapid urbanisation from 1996 to 2019 as evidenced by the rapid expansion of IS. During the past 23 years examined in this study, the IS increased by 930.4 ha 
with an AGR of 40.5 hectares per year (see Table 1). The rapid expansion of the IS was particularly more intense from 2009 onwards, which can be attributed to the ending of the civil war in Sri Lanka. The spatial pattern of the IS growth was mainly observed to expand from the city centre and moving outwards throughout the study temporal extent. The growth pattern of the KUA is similar to other small fast urbanizing cities where the evidence of the UHI effect has been provided [30,32].

The IS expansion also showed a linear development pattern along with the main road network of the KUA, especially towards the southern direction (Figure 3). This growth pattern can be attributed to the fact that Kurunegala city is the centre of the transport hubs in Sri Lanka [56]. For example, Kurunegala city directly connects major capital cities and townships in Sri Lanka, which include Kandy, Colombo, Polonnaruwa, Anuradhapura, Puttalam, Chilaw, Negambo, Kegalle, Matale, Dambulla and Trincomalee through a highway network [56]. This national road network was implemented by the central government to enhance the connectivity of major economic and service providing centres of the country [7]. As a result, the KUA has expanded and experienced rapid urbanisation over the last two decades, as evidenced by the findings of this study.

Additionally, Kurunegala's location as a central connecting city made it possible for the public and other transport systems pass through the city and to connect to other parts of the country. This situation has over the past directly influenced the establishment of improved services such as education, health, real estate, mobility, water supply, food supply, electricity and waste management within Kurunegalla city perimeter and peri-urban areas (i.e., the KUA). The development of better infrastructure and services in the KUA has since led to rapid the urbanisation over the last 23 years examined in this study. As a result, a considerable population in Sri Lanka has been migrating to the KUA to seek better economic and social opportunities. This is also further evidenced by the population growth in Kurunegala District, which increased from 1.2 million in 1981 to an increased 1.6 million in 2012 [57]. The currently proposed mega-city developmental plan aims to establish Kurunegala as the "Transit-Oriented Development Center" with connections of more provincial urban areas [56]. Hence the observed rapid urbanisation and particularly landscape changes (i.e., IS expansion) are expected to continue in the future.

\subsection{Evidence of the UHI Effect in the KUA}

The results revealed that the increase in the IS area occurred at the expense of the GS area and the remaining other land covers in the study area between 1996 and 2019. The GS area declined with an annual rate of -55.5 ha per year (Table 1). These rapid changes in the GS area are consistent with those observed in the other cities in Sri Lanka, such as Colombo [12,19], Kandy [9,55] and Nuwara Eliya $[14,15]$. The rapid urbanisation in the KUA resulted in the conversion of more naturally vegetated areas into the IS from 1996 to 2019. The decreasing trend of the GS area has resulted in the loss of ecosystem services provided by the urban green environment of the study area. This has potentially also caused negative impacts such as the UHI.

The results of this study provide evidence of the UHI effect in the KUA. The results show that the annual mean LST increased by $1.9^{\circ} \mathrm{C}$ from 1996 to 2009, and $3.0^{\circ} \mathrm{C}$ from 2009 to 2019 (Figure 5a). The pattern of the annual mean LST notably increased during the last ten years due to the increase of urban expansion and rapid infrastructure development after the ending of the civil war in 2009. The increase of the annual mean LST in KUA was higher when compared to other cities in Sri Lanka such as Colombo [19] and Kandy [9], which suggests a higher potential to have a faster development of the UHI effect in KUA. The results also show that the UHI is concentrated around the city centre because of the high levels of IS development (Figures 2 and 4 ) in that part of the city. The spatiotemporal pattern of $t$ mean LST, and the FIS, and FGS observed in this study show a clear picture that helps to understand the UHI profile for the study area along the URGZs from the city centre. According to the results, the FIS of the first URGZ increased from $59.9 \%$ to $82.9 \%$, while the FGS reduced from $15.3 \%$ to 1.3\% from 1996 to 2019, respectively (Figure 5a). The rapid development of the artificial surfaces and the rapid decline of the natural surfaces profoundly influenced the increase in mean LST of the city 
centre by $6.1^{\circ} \mathrm{C}$ (from $23.2^{\circ} \mathrm{C}$ to $29.4{ }^{\circ} \mathrm{C}$ ) between 1996 and 2019. The statistical analysis shows that mean LST had a significant relationship (positive) with the FIS in the three-time points. The coefficient of determination $\left(R^{2}\right)$ increased from 0.87 to 0.95 between 1996 and 2019, respectively. In addition, the mean LST showed a significant negative relationship with the FGS (Figure $5 b$ ). The $R^{2}$ increased from 0.66 to 0.83 during the investigation period. The mean LST of both the IS and GS revealed an increasing trend (Table 2a). However, the increase in mean LST for IS had a higher value than the GS in all the study time points. The magnitude of UHI between the IS and the GS revealed a continuously increasing pattern; $1.2{ }^{\circ} \mathrm{C}$ for $1996,1.7^{\circ} \mathrm{C}$ for 2009 and $2 .{ }^{\circ} \mathrm{C}$ for 2019 (Table 2b). The observed increasing patterns are different from other cities in Sri Lanka [9]. However, the magnitude of UHI among IS and GS are comparable with previous studies for the other cities in the world, such as Bangkok (Thailand), Manila (Philippines) [26] and Seoul (South Korea) [33].

The multidirectional and multi-temporal analysis of mean LST and the FIS can also help to understand the urbanisation pattern of the study area and its impact on enhancing the UHI profile of the city. The analyses showed that IS development largely occurred around the city centre (Figure 6). The UHI formation showed an increasing trend of IS occurring mainly in the north, south, east and northwest compared to the west, northeast, southwest and southeast of the study area. Therefore, future urban policies and planning strategies on UHI mitigation should have a strong focus on the north, south, east and northwest directions. In addition, the mixture of LULC would provide a significant contribution to minimizing UHI [70].

The grid-based analysis gives a clear picture of the distribution pattern of the mean LST, and the FIS, and FGS over time. These developmental patterns can be used as a proxy indicator to capture future developmental patterns. The statistical analysis revealed that the mean LST had a positive relationship with the FIS from 1996 to 2019 (Figure 7b). The $R^{2}$ increased from 0.05 to 0.48 from 1996 to 2009. On the other hand, mean LST had a significant relationship (negative) with the FGS from 1996 to 2019. The $\mathrm{R}^{2}$ shows increasing pattern by $0.10,0.31$ and 0.41 in 1996, 2009 and 2019, respectively (Figure $7 \mathrm{~b}$ ). These results confirm the importance of the GS area towards the mitigation of the UHI effect resulting from the increase in IS.

\subsection{Implications for UHI Mitigation and NBS}

The results of this study reflect the impact of urban landscape changes on LST in urban areas and its significant contribution to the incidence of the UHI effect. The results can be used to support urban planners and managers in designing how to spatially mix the development of IS with GS area GS to maintain an acceptable and healthy thermal comfort in the city. The future development of the KUA needs a mixed development of IS and GS along with NBS. As a developing country, Sri Lanka has more possibilities to use NBS for UHI mitigation than the use of other engineering solutions. There is a need to consider urban green-blue space management (conversion of urban built-up areas into urban blue-green spaces) as one of the key NBS approaches [71] to mitigate the UHI effects in the city and the peri-urban regions [72]. On the other hand, vertical development should also be encouraged rather than horizontal development to keep more land spaces for NBS. In addition, the city council needs to make people aware by apply guidelines of green and environment-friendly buildings at all stages of the life cycle of buildings such as planning, constructing, operating and maintenance [53]. The existing buildings should consider utilizing green walls to minimize the UHI effects; a previous study has shown that the use of green walls helps to decrease the indoor temperature by $2.4{ }^{\circ} \mathrm{C}$ [73].

The use of NBS in the context of city planning is particularly critical to understand how multifunctional NBS components interact with each other within the urban socio-spatial context [48]. NBS is very well applied interactively with an even small extent of natural or modified ecosystems to deliver expected benefits [72]. Kurunegala city only occupies a small land area (1100 ha), with nearly two-thirds of the total city area covered by built-up [74]. The rest of the land in the KUA is occupied by peri-urban areas $(11,000 \mathrm{ha}$ ) that surround the city. Thus, the city contains a considerable amount of green-blue spaces. Therefore, considering the observed pattern of urban development and urban 
morphology of the KUA in this study, this opens a new window for the city planning authorities to identify and integrate the NBS into the overall city planning process. The study recommends two NBS approaches that have the potential to mitigate the heat stress; (i) infrastructure-related approaches for the KUA area and (ii) Issue-specific ecosystem-related approaches for the peri-urban DSD area [50]. Based on the built-up categories in the Kurunegala Municipal Council area, we suggest two types of strategies for the KUA; (i) conversion of grey infrastructure to green infrastructures using natural or semi-natural systems providing UHI management options with co-benefits, and (ii) low impact development strategies land planning and engineering design approaches incorporating GS as part of the infrastructure to manage the UHI effect.

Of note is that there are no direct national or subnational policies or strategies addressing the UHI mitigation in the urban areas of Sri Lanka [74]. However, after reviewing the physical and spatial planning, environment protection and climate change policies as well as strategies related to urban development, there are several implicit strategies and actions recommended to mitigate and adapt to the UHI effect [75]. On the other hand, due to the current urban densification and high demand for urban infrastructure and services, the scale and extent of greening in urban areas can be in conflict with land use regulations and priorities of the local authorities. Hence sustainable urban nature-based innovations with co-benefits to the society need to be carefully explored by working with communities and stakeholders.

\subsection{Limitations of the Study}

In this study, we did not analyse the NBS by using specific analysis method due to the lack of data related to the NBS of the study area. We recommenced future research to analyse data for NBS, if available, and come up with specific advices on how to mitigate the effects of the UHI effect based on NBS.

\section{Conclusions}

This study examined the spatiotemporal variation of the UHI in the KUA from 1996 to 2019. We used several indices and methods, including annual median land surface temperature based on the GEE, the spectral index-based method for land cover extraction, Urban-Rural Gradient Zone, multitemporal and multi-directional UHI profiles and Grid-Based Analysis. The results of this study show that the KUA experienced rapid urban expansion during the last 23 years. These developments area evidenced by the rapid expansion of the IS with an AGR of 40.5 ha per year and the rapid decline of GS at an annual loss rate of -55.5 ha per year. The rapid land cover changes in the study area directly influenced the increase in the mean LST of the city which was $21.6^{\circ} \mathrm{C}$ in $1996,23.5^{\circ} \mathrm{C}$ in 2009 and $26.5^{\circ} \mathrm{C}$ in 2019 . These changes in the LST resulted in the generation of the UHI in the KUA. The study has revealed two different patterns of the UHI in the KUA and surrounding peri-urban areas. In the KUA area, a higher magnitude of UHI occurs because of the high proportion of grey infrastructure and high anthropomorphic activities. In the peri-urban areas, where there is large green-blue space as well as less built-up area, and anthropogenic heat, a lower impact of the UHI occurs. The study recommends interactively applying NBS to addressing the UHI impacts with effective mitigation and adaptation measures for urban sustainability.

Author Contributions: The author to receive correspondence, Manjula Ranagalage, proposed the topic and spearheaded the data processing and analysis, as well as the writing of the manuscript; Sujith S. Ratnayake, contributed to the conceptualization, analysis, and writing the manuscript; DMSLB Dissanayake, Lalit Kumar, Hasula Wickremasinghe, Jagathdeva Vidanagama, Hanna Cho, Susantha Udagedara, Keshav Kumar Jha, Matamyo Simwanda, Darius Phiri, ENC Perera and Priyantha Muthunayake helped in the writing and editing of the manuscript. All authors have read and agreed to the published version of the manuscript.

Funding: The authors received no funding for this study.

Acknowledgments: The authors appreciate the United States Geological Survey (USGS) for the provision of the dataset used in this research work. The comments and suggestions of the anonymous reviewers are gratefully acknowledged. 
Conflicts of Interest: We declare we have no competing interests.

\section{Abbreviations}

$\begin{array}{ll}\text { FGS } & \text { Fraction of GS } \\ \text { FIS } & \text { Fraction of IS } \\ \text { GEE } & \text { Google Earth Engine } \\ \text { GHG } & \text { Green House Gas } \\ \text { GS } & \text { Green Surface } \\ \text { IS } & \text { Impervious Surface } \\ \text { KUA } & \text { Kurunegala Urban Area } \\ \text { LST } & \text { Land surface temperature } \\ \text { LULC } & \text { Land Use/Land Cover } \\ \text { MNDWI } & \text { Modified Normalized Difference Water Index } \\ \text { NBS } & \text { Nature-Based Solutions } \\ \text { NDVI } & \text { Normalized Difference Vegetation Index } \\ \text { NIR } & \text { Near-Infrared } \\ \text { OS } & \text { Other Surface } \\ \text { RS } & \text { Remote Sensing } \\ \text { UHI } & \text { Urban Heat Island } \\ \text { URGZ } & \text { Urban-Rural Gradient Zone } \\ \text { VrNIR-BI } & \text { Visible Red and NIR based Built-up Index }\end{array}$

\section{Appendix A}

Table A1. Properties of the Landsat images (Level 2) used in this study.

\begin{tabular}{|c|c|c|c|}
\hline Sensor & Scene ID & Acquisition Date & Time (GMT) \\
\hline \multirow{16}{*}{ Landsat $5 \mathrm{TM}$} & LT05_L1TP_141055_19960221_20170106_01_T1 & $1996-02-21$ & 03:59:45 \\
\hline & LT05_L1TP_141055_19960308_20170106_01_T1 & 1996-03-08 & 04:00:49 \\
\hline & LT05_L1TP_141055_19960324_20170105_01_T1 & 1996-03-24 & 04:01:51 \\
\hline & LT05_L1TP_141055_19960409_20170105_01_T1 & 1996-04-09 & 04:02:51 \\
\hline & LT05_L1TP_141055_19960425_20170104_01_T1 & $1996-04-25$ & 04:03:49 \\
\hline & LT05_L1TP_141055_19960511_20170104_01_T1 & 1996-05-11 & 04:04:46 \\
\hline & LT05_L1TP_141055_19960527_20170104_01_T1 & $1996-05-27$ & 04:05:41 \\
\hline & LT05_L1TP_141055_19960714_20170104_01_T1 & 1996-07-14 & 04:08:15 \\
\hline & LT05_L1TP_141055_19960730_20170103_01_T1 & 1996-07-30 & 04:09:06 \\
\hline & LT05_L1TP_141055_19960815_20170103_01_T1 & $1996-08-15$ & 04:09:56 \\
\hline & LT05_L1TP_141055_19960831_20170103_01_T1 & 1996-08-31 & 04:10:48 \\
\hline & LT05_L1TP_141055_19960916_20170102_01_T1 & 1996-09-16 & 04:11:41 \\
\hline & LT05_L1TP_141055_19961002_20170102_01_T1 & 1996-10-02 & $04: 12: 33$ \\
\hline & LT05_L1TP_141055_19961103_20170102_01_T1 & 1996-11-03 & 04:14:09 \\
\hline & LT05_L1TP_141055_19961119_20170101_01_T1 & 1996-11-19 & 04:14:53 \\
\hline & LT05_L1TP_141055_19961205_20170101_01_T1 & $1996-12-05$ & 04:15:40 \\
\hline \multirow{18}{*}{ Landsat 5 TM } & LT05_L1TP_141055_20090107_20161028_01_T1 & 2009-01-07 & $04: 38: 46$ \\
\hline & LT05_L1TP_141055_20090123_20161028_01_T1 & $2009-01-23$ & 04:39:12 \\
\hline & LT05_L1TP_141055_20090208_20161028_01_T1 & 2009-02-08 & 04:39:37 \\
\hline & LT05_L1TP_141055_20090224_20161029_01_T1 & $2009-02-24$ & 04:40:01 \\
\hline & LT05_L1TP_141055_20090312_20161029_01_T1 & 2009-03-12 & $04: 40: 23$ \\
\hline & LT05_L1TP_141055_20090328_20161027_01_T1 & 2009-03-28 & $04: 40: 45$ \\
\hline & LT05_L1TP_141055_20090429_20161026_01_T1 & 2009-04-29 & $04: 41: 22$ \\
\hline & LT05_L1TP_141055_20090515_20161026_01_T1 & 2009-05-15 & 04:41:40 \\
\hline & LT05_L1TP_141055_20090616_20161025_01_T1 & 2009-06-16 & $04: 42: 15$ \\
\hline & LT05_L1TP_141055_20090702_20161024_01_T1 & 2009-07-02 & $04: 42: 32$ \\
\hline & LT05_L1TP_141055_20090718_20161027_01_T1 & 2009-07-18 & $04: 42: 49$ \\
\hline & LT05_L1TP_141055_20090803_20161022_01_T1 & 2009-08-03 & 04:43:03 \\
\hline & LT05_L1TP_141055_20090819_20161022_01_T1 & 2009-08-19 & $04: 43: 17$ \\
\hline & LT05_L1TP_141055_20090904_20161021_01_T1 & 2009-09-04 & 04:43:32 \\
\hline & LT05_L1TP_141055_20090920_20161020_01_T1 & 2009-09-20 & $04: 43: 44$ \\
\hline & LT05_L1TP_141055_20091006_20161024_01_T1 & 2009-10-06 & $04: 43: 55$ \\
\hline & LT05_L1TP_141055_20091022_20161019_01_T1 & $2009-10-22$ & 04:44:05 \\
\hline & LT05_L1TP_141055_20091123_20161018_01_T1 & $2009-11-23$ & 04:44:19 \\
\hline
\end{tabular}


Table A1. Cont.

\begin{tabular}{|c|c|c|c|}
\hline Sensor & Scene ID & Acquisition Date & Time (GMT) \\
\hline \multirow{18}{*}{ Landsat $8 \mathrm{OLI} / \mathrm{TIRS}$} & LC08_L1TP_141055_20190103_20190130_01_T1 & 2019-01-03 & 04:53:47 \\
\hline & LC08_L1TP_141055_20190119_20190201_01_T1 & 2019-01-19 & $04: 53: 44$ \\
\hline & LC08_L1TP_141055_20190220_20190220_01_T1 & $2019-02-20$ & 04:53:38 \\
\hline & LC08_L1TP_141055_20190308_20190324_01_T1 & 2019-03-08 & 04:53:33 \\
\hline & LC08_L1TP_141055_20190324_20190403_01_T1 & 2019-03-24 & 04:53:29 \\
\hline & LC08_L1TP_141055_20190409_20190422_01_T1 & 2019-04-09 & $04: 53: 25$ \\
\hline & LC08_L1TP_141055_20190425_20190508_01_T1 & 2019-04-25 & 04:53:18 \\
\hline & LC08_L1TP_141055_20190511_20190521_01_T1 & 2019-05-11 & $04: 53: 27$ \\
\hline & LC08_L1TP_141055_20190527_20190605_01_T1 & 2019-05-27 & 04:53:36 \\
\hline & LC08_L1TP_141055_20190612_20190619_01_T1 & 2019-06-12 & $04: 53: 43$ \\
\hline & LC08_L1TP_141055_20190628_20190706_01_T1 & 2019-06-28 & 04:53:49 \\
\hline & LC08_L1TP_141055_20190714_20190719_01_T1 & 2019-07-14 & 04:53:52 \\
\hline & LC08_L1TP_141055_20190730_20190801_01_T1 & 2019-07-30 & $04: 53: 57$ \\
\hline & LC08_L1TP_141055_20190815_20190820_01_T1 & 2019-08-15 & 04:54:03 \\
\hline & LC08_L1TP_141055_20190831_20190916_01_T1 & 2019-08-31 & 04:54:07 \\
\hline & LC08_L1TP_141055_20191002_20191018_01_T1 & 2019-10-02 & 04:54:17 \\
\hline & LC08_L1TP_141055_20191018_20191029_01_T1 & 2019-10-18 & 04:54:19 \\
\hline & LC08_L1TP_141055_20191103_20191115_01_T1 & 2019-11-03 & $04: 54: 18$ \\
\hline
\end{tabular}

\section{References}

1. The World Bank. New Country Classifications by Income Level: 2019-2020. Available online: https: //blogs.worldbank.org/opendata/new-country-classifications-income-level-2019-2020 (accessed on 20 March 2020).

2. The World Bank. 2020 Total Population-Sri Lanka. World Bank. Available online: https://data.worldbank. org/indicator/SP.POP.TOTL?locations=LK\&view=chart (accessed on 20 March 2020).

3. The World Bank. 2020 Urban Population-Sri Lanka. World Bank. Available online: https://data.worldbank. org/indicator/SP.URB.TOTL?end=2018\&locations=LK\&name_desc=true\&start=1960\&view=chart $($ accessed on 19 March 2020).

4. The World Bank. The World Bank in Sri Lanka. Available online: https://www.worldbank.org/en/country/ srilanka/overview (accessed on 10 June 2020).

5. Zimmerman, T. The New Silk Roads: China, the U.S., and the Future of Central Asia; Center on International Cooperation: New York, NY, USA, 2015; pp. 1-26.

6. Subasinghe, S.; Estoque, R.C.; Murayama, Y. Spatiotemporal analysis of urban growth using GIS and remote sensing: A case study of the Colombo Metropolitan Area, Sri Lanka. ISPRS Int. J. Geo-Inf. 2016, 5, 197. [CrossRef]

7. Road Development Authority. 2020. Available online: http://www.rda.gov.lk/source/rda_roads.htm (accessed on 20 March 2020).

8. National Physical Planning Department of Sri Lanka. National Physical Planning Policy \& The Plan-2017-2050; National Physical Planning Department: Battaramulla, Sri Lanka, 2017.

9. Ranagalage, M.; Dissanayake, D.; Murayama, Y.; Zhang, X.; Estoque, R.C.; Perera, E.; Morimoto, T. Quantifying surface urban heat island formation in the World Heritage tropical mountain city of Sri Lanka. ISPRS Int. J. Geo-Inf. 2018, 7, 341. [CrossRef]

10. Estoque, R.C.; Murayama, Y. Quantifying landscape pattern and ecosystem service value changes in four rapidly urbanizing hill stations of Southeast Asia. Landsc. Ecol. 2016, 31, 1481-1507. [CrossRef]

11. Azam, M.; Khan, A. Urbanization and environmental degradation: Evidence from four SAARC countries-Bangladesh. Environ. Prog. Sustain. Energy. 2016, 35, 823-832. [CrossRef]

12. Ranagalage, M.; Estoque, R.C.; Zhang, X.; Murayama, Y. Spatial changes of urban heat island formation in the Colombo District, Sri Lanka: Implications for sustainability planning. Sustainability 2018, 10, 1367. [CrossRef]

13. Weerasundara, L.; Amarasekara, R.W.K.; Magana-Arachchi, D.N.; Ziyath, A.M.; Karunaratne, D.G.G.P.; Goonetilleke, A.; Vithanage, M. Microorganisms and heavy metals associated with atmospheric deposition in a congested urban environment of a developing country: Sri Lanka. Sci. Total Environ. 2017, 584-585, 803-812. [CrossRef] 
14. Ranagalage, M.; Wang, R.; Gunarathna, M.H.J.P.; Dissanayake, D.; Murayama, Y.; Simwanda, M. Spatial forecasting of the landscape in rapidly urbanizing hill stations of South Asia: A case study of Nuwara Eliya, Sri Lanka (1996-2037). Remote Sens. 2019, 11, 1743. [CrossRef]

15. Ranagalage, M.; Murayama, Y.; Dissanayake, D.; Simwanda, M. The impacts of landscape changes on annual mean land surface temperature in the tropical mountain city of Sri Lanka: A case study of Nuwara Eliya (1996-2017). Sustainability 2019, 11, 5517. [CrossRef]

16. Sirisena, P.; Noordeen, F.; Kurukulasuriya, H. Effect of climatic factors and population density on the distribution of dengue in Sri Lanka: A GIS based evaluation for prediction of outbreaks. PLoS ONE 2017, 12, e0166806. [CrossRef]

17. Gunawardena, A.; Hailu, A.; White, B.; Pandit, R. Estimating marginal abatement costs for industrial water pollution in Colombo. Environ. Dev. 2017, 21, 26-37. [CrossRef]

18. Hettiarachchi, M.; Morrison, T.H.; Wickramsinghe, D.; Mapa, R.; De Alwis, A.; McAlpine, C.A. The eco-social transformation of urban wetlands: A case study of Colombo, Sri Lanka. Landsc. Urban Plan. 2014, 132, 55-68. [CrossRef]

19. Ranagalage, M.; Estoque, R.C.; Murayama, Y. An urban heat island study of the Colombo metropolitan area, Sri Lanka, based on Landsat Data (1997-2017). ISPRS Int. J. Geo-Inf. 2017, 6, 189. [CrossRef]

20. EPA (US Environmental Protection Agency). Reducing Urban Heat Islands: Compendium of Strategies Urban Heat Island Basics; US Environmental Protection Agency: Washington, DC, USA, 2008; pp. 1-22.

21. Arnfield, A.J. Two decades of urban climate research: A review of turbulence, exchanges of energy and water, and the urban heat island. Int. J. Climatol. 2003, 26, 1-26. [CrossRef]

22. Arbuthnott, K.G.; Hajat, S. The health effects of hotter summers and heat waves in the population of the United Kingdom: A review of the evidence. Environ. Health 2017, 16, 119. [CrossRef] [PubMed]

23. Huang, J.; Gurney, K.R. The variation of climate change impact on building energy consumption to building type and spatiotemporal scale. Energy 2016, 111, 137-153. [CrossRef]

24. Sri Lanka Sustainable Energy Authority, Guideline for Sustainable Energy Residences in Sri Lanka; Sri Lanka Sustainable Energy Authority: Colombo, Sri Lanka, 2019; Volume 94.

25. Papakostas, K.; Mavromatis, T.; Kyriakis, N. Impact of the ambient temperature rise on the energy consumption for heating and cooling in residential buildings of Greece. Renew. Energy 2010, 35, 1376-1379. [CrossRef]

26. Estoque, R.C.; Murayama, Y.; Myint, S.W. Effects of landscape composition and pattern on land surface temperature: An urban heat island study in the megacities of Southeast Asia. Sci. Total Environ. 2017, 577, 349-359. [CrossRef]

27. Teferi, E.; Abraha, H. Urban heat island effect of Addis Ababa city: Implications of urban green spaces for climate change adaptation. In Climate Change Adaptation in Africa; Springer: Berlin/Heidelberg, Germany, 2014.

28. Kikon, N.; Singh, P.; Singh, S.K.; Vyas, A. Assessment of urban heat islands (UHI) of Noida City, India using multi-temporal satellite data. Sustain. Cities Soc. 2016, 22, 19-28. [CrossRef]

29. Dousset, B.; Gourmelon, F. Satellite multi-sensor data analysis of urban surface temperatures and landcover. ISPRS J. Photogramm. Remote Sens. 2003, 58, 43-54. [CrossRef]

30. Estoque, R.C.; Murayama, Y. Monitoring surface urban heat island formation in a tropical mountain city using Landsat data (1987-2015). ISPRS J. Photogramm. Remote Sens. 2017, 133, 18-29. [CrossRef]

31. Simwanda, M.; Ranagalage, M.; Estoque, R.C.; Murayama, Y. Spatial analysis of surface urban heat islands in four rapidly growing African cities. Remote Sens. 2019, 11, 1645. [CrossRef]

32. Dissanayake, D.; Morimoto, T.; Murayama, Y.; Ranagalage, M. Impact of landscape structure on the variation of land surface temperature in sub-saharan region: A case study of Addis Ababa using Landsat data (1986-2016). Sustainability 2019, 11, 2257. [CrossRef]

33. Priyankara, P.; Ranagalage, M.; Dissanayake, D.; Morimoto, T.; Murayama, Y. Spatial process of surface urban heat island in rapidly growing Seoul metropolitan area for sustainable urban planning using Landsat data. Climate 2019, 7, 110. [CrossRef] 
34. Gholoobi, M.; Tayyebi, A.; Taleai, M.; Tayyebi, A. Comparing pixel based and object based approaches in land use classification in mountainous areas. Int. Arch. Photogramm. Remote Sens. Spat. Inf. Sci. 2010, XXXVIII, 789-794.

35. Myint, S.W.; Gober, P.; Brazel, A.; Grossman-Clarke, S.; Weng, Q. Per-pixel vs. object-based classification of urban land cover extraction using high spatial resolution imagery. Remote Sens. Environ. 2011, 115, 1145-1161. [CrossRef]

36. Estoque, R.C.; Murayama, Y. Classification and change detection of built-up lands from Landsat-7 ETM+ and Landsat-8 OLI/TIRS imageries: A comparative assessment of various spectral indices. Ecol. Indic. 2015, 56, 205-217. [CrossRef]

37. Ranagalage, M.; Estoque, R.C.; Handayani, H.H.; Zhang, X.; Morimoto, T.; Tadono, T.; Murayama, Y. Relation between urban volume and land surface temperature: A comparative study of planned and traditional cities in Japan. Sustainability 2018, 10, 2366. [CrossRef]

38. Voogt, J.A.; Oke, T.R. Thermal remote sensing of urban climates. Remote Sens. Environ. 2003, 86, 370-384. [CrossRef]

39. Xiao, R.; Ouyang, Z.; Zheng, H.; Li, W.; Schienke, E.W.; Wang, X. Spatial pattern of impervious surfaces and their impacts on land surface temperature in Beijing, China. J. Environ. Sci. 2007, 19, 250-256. [CrossRef]

40. Myint, S.W.; Brazel, A.; Okin, G.; Buyantuyev, A. Combined effects of impervious surface and vegetation cover on air temperature variations in a rapidly expanding desert city. GIScience Remote Sens. 2010, 47, 301-320. [CrossRef]

41. EPA (US Environmental Protection Agency). Reducing Urban Heat Islands: Compendium of Strategies-Cool Roofs; US Environmental Protection Agency: Washington, DC, USA, 2008; pp. 1-31.

42. EPA (US Environmental Protection Agency). Reducing Urban Heat Islands: Compendium of Strategies-Green Roofs; US Environmental Protection Agency: Washington, DC, USA, 2008; pp. 1-29.

43. EPA (US Environmental Protection Agency). Reducing Urban Heat Islands Compendium Strategies- Cool Pavements; US Environmental Protection Agency: Washington, DC, USA, 2008; pp. 1-40.

44. Harris, R.; Coutts, A. Airborne Thermal Remote Sensing for Analysis of the Urban Heat Island; Victoria Center for Climate Change Research: Melbourne, Australia, 2011; pp. 1-34.

45. Rosenzweig, C.; Solecki, W.; Parshall, L.; Gaffin, S.; Lynn, B.; Goldberg, R.; Cox, J.; Hodges, S. Mitigating New York City's heat island with urban forestry, living roofs, and light surfaces. Presented at the 86th American Meteorological Society Annual Meeting, Atlanta, GA, USA, 30 January-2 February 2006.

46. Wong, N.H.; Chen, Y.; Ong, C.L.; Sia, A. Investigation of thermal benefits of rooftop garden in the tropical environment. Build. Environ. 2003, 38, 261-270. [CrossRef]

47. Dorst, H.; van der Jagt, A.; Raven, R.; Runhaar, H. Urban greening through nature-based solutions-Key characteristics of an emerging concept. Sustain. Cities Soc. 2019, 49, 101620. [CrossRef]

48. Albert, C.; Schröter, B.; Haase, D.; Brillinger, M.; Henze, J.; Herrmann, S.; Gottwald, S.; Guerrero, P.; Nicolas, C.; Matzdorf, B. Addressing societal challenges through nature-based solutions: How can landscape planning and governance research contribute? Landsc. Urban Plan. 2019, 182, 12-21. [CrossRef]

49. Van der Jagt, A.P.N.; Szaraz, L.R.; Delshammar, T.; Cvejić, R.; Santos, A.; Goodness, J.; Buijs, A. Cultivating nature-based solutions: The governance of communal urban gardens in the European Union. Environ. Res. 2017, 159, 264-275. [CrossRef] [PubMed]

50. Cohen-Shacham, E.; Walters, G.; Janzen, C.; Maginnis, S. Nature-Based Solutions to Address Global Societal Challenges; IUCN: Gland, Switzerland, 2016.

51. Oke, T.R. Initial Guidance to Obtain Representative Meteorological Observations at Urban Sites. Available online: http://blogs.ubc.ca/toke/files/2015/12/IOM-81-UrbanMetObs.pdf (accessed on 10 June 2020).

52. Senanayake, I.P.; Welivitiya, W.D.D.P.; Nadeeka, P.M. Remote sensing based analysis of urban heat islands with vegetation cover in Colombo city, Sri Lanka using Landsat-7 ETM+ data. Urban Clim. 2013, 5, 19-35. [CrossRef]

53. Dissanayake, D. Land use change and Its impacts on land surface temperature in Galle city, Sri Lanka. Climate 2020, 8, 65. [CrossRef] 
54. Dissanayake, D.; Morimoto, T.; Murayama, Y.; Ranagalage, M.; Perera, E. Analysis of life quality in a tropical mountain city using a multi-criteria geospatial technique: A case study of Kandy City, Sri Lanka. Sustainability 2020, 12, 2918. [CrossRef]

55. Dissanayake, D.; Morimoto, T.; Ranagalage, M.; Murayama, Y. Land-use/land-cover changes and their impact on surface urban heat islands: Case study of Kandy City, Sri Lanka. Climate 2019, 7, 99. [CrossRef]

56. Urban Development Authority; North Western Province Office. Kurunegala Town Development Plan 2019-2030; UDA: Battaramulla, Sri Lanka, 2019.

57. Department of Census \& Statistics. Census of Population and Housing. 2012. Available online: http://www. statistics.gov.lk/pophousat/cph2011/index.php?fileName=Activities/TentativelistofPublications (accessed on 25 March 2017).

58. Yu, Z.; Di, L.; Tang, J.; Zhang, C.; Lin, L.; Yu, E.G.; Rahman, M.S.; Gaigalas, J.; Sun, Z. Land use and land cover classification for Bangladesh 2005 on google earth engine. In Proceedings of the 2018 7th International Conference on Agro-Geoinformatics (Agro-Geoinformatics), Hangzhou, China, 6-9 August 2018.

59. Ravanelli, R.; Nascetti, A.; Cirigliano, R.V.; Di Rico, C.; Leuzzi, G.; Monti, P.; Crespi, M. Monitoring the impact of land cover change on surface urban heat island through Google Earth Engine: Proposal of a global methodology, first applications and problems. Remote Sens. 2018, 10, 1488. [CrossRef]

60. Parastatidis, D.; Mitraka, Z.; Chrysoulakis, N.; Abrams, M. Online global land surface temperature estimation from Landsat. Remote Sens. 2017, 9, 1208. [CrossRef]

61. Otsu, N. A Threshold Selection Method from Gray-Level Histograms. IEEE Trans. Syst. Man Cybern. 1979, 9, 62-66. [CrossRef]

62. Li, W.; Du, Z.; Ling, F.; Zhou, D.; Wang, H.; Gui, Y.; Sun, B.; Zhang, X. A comparison of land surface water mapping using the normalized difference water index from TM, ETM+ and ALI. Remote Sens. 2013, 5, 5530-5549. [CrossRef]

63. Sobrino, J.A.; Jiménez-Muñoz, J.C.; Paolini, L. Land surface temperature retrieval from LANDSAT TM 5. Remote Sens. Environ. 2004, 90, 434-440. [CrossRef]

64. Dissanayake, D.; Morimoto, T.; Ranagalage, M. Accessing the soil erosion rate based on RUSLE model for sustainable land use management: A case study of the Kotmale watershed, Sri Lanka. Model. Earth Syst. Environ. 2019, 5, 291-306. [CrossRef]

65. Congalton, R.G. A review of assessing the accuracy of classifications of remotely sensed data. Remote Sens. Environ. 1991, 37, 35-46. [CrossRef]

66. Weng, Q.; Lu, D.; Schubring, J. Estimation of land surface temperature-vegetation abundance relationship for urban heat island studies. Remote Sens. Environ. 2004, 89, 467-483. [CrossRef]

67. Rousta, I.; Sarif, M.O.; Gupta, R.D.; Olafsson, H.; Ranagalage, M.; Murayama, Y.; Zhang, H.; Mushore, T.D. Spatiotemporal analysis of land use/land cover and its effects on surface urban heat island using Landsat Data: A case study of Metropolitan City Tehran (1988-2018). Sustainability 2018, 10, 4433. [CrossRef]

68. Dissanayake, D.; Morimoto, T.; Ranagalage, M.; Murayama, Y. Impact of urban surface characteristics and socio-economic variables on the spatial variation of land surface temperature in Lagos City, Nigeria. Sustainability 2019, 11, 25. [CrossRef]

69. Anderson, J.R. A Land Use and Land Cover Classification System for Use with Remote Sensor Data; Geological Survey Professional Paper; USGS: Reston, VA, USA, 1976.

70. Thanh Hoan, N.; Liou, Y.-A.; Nguyen, K.-A.; Sharma, R.; Tran, D.-P.; Liou, C.-L.; Cham, D. Assessing the effects of land-use types in surface urban heat islands for developing comfortable living in Hanoi City. Remote Sens. 2018, 10, 1965. [CrossRef]

71. Fan, P.; Ouyang, Z.; Basnou, C.; Pino, J.; Park, H.; Chen, J. Nature-based solutions for urban landscapes under post-industrialization and globalization: Barcelona versus Shanghai. Environ. Res. 2017, 156, $272-283$. [CrossRef]

72. Raymond, C.M.; Frantzeskaki, N.; Kabisch, N.; Berry, P.; Breil, M.; Nita, M.R.; Geneletti, D.; Calfapietra, C. A framework for assessing and implementing the co-benefits of nature-based solutions in urban areas. Environ. Sci. Policy 2017, 77, 15-24. [CrossRef]

73. Galagoda, R.U.; Jayasinghe, G.Y.; Halwatura, R.U.; Rupasinghe, H.T. The impact of urban green infrastructure as a sustainable approach towards tropical micro-climatic changes and human thermal comfort. Urban For. Urban Green. 2018, 34, 1-9. [CrossRef] 
74. UN-Habitat. The State of Sri Lankan Cities (2018). Available online: http://unhabitat.lk/wp-content/uploads/ 2018/12/SoSLC_Report_Final_Low-r.pdf (accessed on 10 June 2020).

75. World Bank Group. Sri Lanka (Intended) International Bank for Reconstruction and Development/the World Bank Sri Lanka (Intended) Nationally Determined Contributions ((I)NDCs); World Bank Group: Washington, DC, USA, 2016.

(c)

(C) 2020 by the authors. Licensee MDPI, Basel, Switzerland. This article is an open access article distributed under the terms and conditions of the Creative Commons Attribution (CC BY) license (http://creativecommons.org/licenses/by/4.0/). 